\title{
A comparison of spectrometric methods and methods based on electrochemical principles
}

\author{
Branislav Hric ${ }^{1}$, Jan Suchánek ${ }^{1,2}$, Ivana Bartlová ${ }^{2}$ Michal Dostal, ${ }^{1,}$, Pavel Kubát ${ }^{2}$, Svatopluk Civiš², \\ Vaclav Nevrly' ', Petr Bitala', Vaclav Valek', Zdeněk Zelinger ${ }^{2}$ \\ ${ }^{1}$ VŠB-Technical University of Ostrava, Faculty of Safety Engineering, Ostrava, Czech \\ Republic; branislav.hric@vsb.cz; \\ 2 J. Heyrovský Institute of Physical Chemistry, v.v.i., Academy of Sciences of the Czech Republic, \\ Prague, Czech Republic; zdenek.zelinger@jh-inst.cas.cz
}

\begin{abstract}
Gas detection systems are an important tool for the prevention of accidents, and mitigation of their impact on human life and health. The ideal sensor is selective and has fast, stable and repeatable response to a particular analyte. Over the time it has been shown that various detection principles have led only to partial fulfilment of this ideal. Compromises have to be made according to desired application of the sensor and resulting demands on the sensor parameters, including its price. In this study, the properties of semiconductor, electrochemical and tunable diode laser based sensors are evaluated and compared. The sensors are tested with selected chemicals such as VOCs (Volatile Organic Compounds - methanol) and methane. The advantages and disadvantages are summarized and the possibilities of their use are discussed.
\end{abstract}

Key words: sensors, resistance, flow, methanol, furnace

\section{Introduction}

Gas detection has an impact across a wide range of applications. Early markets have included the process and petrochemical industries, where sensors are used to ensure safety (e.g. via detection of toxic or flammable gases), monitor feedstocks and measure key species in products and processes, some of which can be rapidly changing [1].

Use of high sensitivity gas detectors is widespread in atmospheric science, where they are used to measure and understand the profile and pathways of different gas species including greenhouse gases [1].

Quantitative detection of gases is traditionally dominated by laboratory analytical equipment such as gas chromatographs, with sampling that precludes real-time data, or small ultra-lowcost devices such as pellistors, semiconductor gas sensors or electrochemical devices [1].

In contrast, gas sensors based on optical absorption offer fast responses (time constants below $1 \mathrm{~s}$ are possible), minimal drift and high gas specificity, with zero cross-response to other gases as long as their design is carefully considered. Measurements can be made in real time and in situ without disturbing the gas sample, which can be important in process control.
Because the transduction method makes a direct measurement of a molecule's physical properties (its absorption at a specific wavelength) drift is reduced and, because the incident light intensity can be determined, measurements are self-referenced making them inherently reliable. In this way, optical gas sensing fills an important gap between lower cost sensors with inferior performance and high end laboratory equipment [1].

\section{Experiment}

1) SENSOR: Pellistor - Measured $\mathrm{CH}_{3} \mathrm{OH}$ (methanol)

A pellistor is device used to detect gases which are either combustible or which have a significant difference in thermal conductivity to that of air. The word "pellistor" is a combination of pellet and resistor. The detecting element consist of small "pellets" of catalyst loaded ceramic whose resistance changes in the presence of gas. Many of them require to be gently heated in use, so they may be four terminal devices with two connections for a small heating element and two to the sensor itself. To avoid any risk of explosion, the sensitive element is usually enclosed in a wire mesh housing. More robust sensors for use in high risk environments may have solid steel housing with a gas port of sintered metal granules. 
Both of these work in a manner similar to the Davy safety lamp; gas may percolate through the permeable mesh, but the passages are too long and narrow to support the propagation of a flame [2].

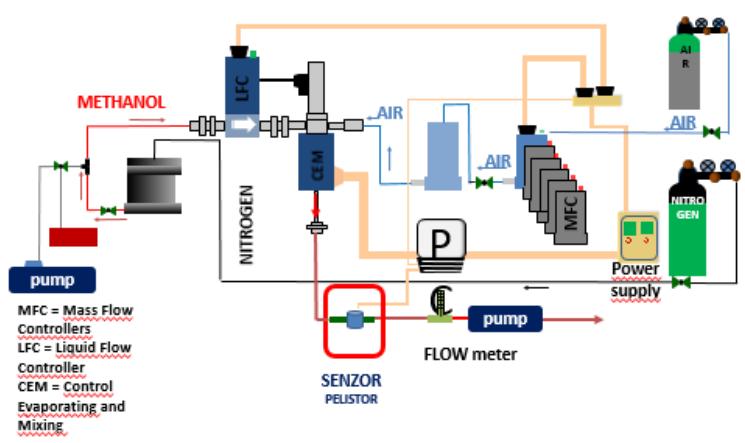

Fig. 1. Scheme of experimental arrangement [3].

The foundation of this configuration is the carrier gas Air and Gas Mixing System, which, depending on the flow rate creates a desired gas concentration. Thus, diluted gas continues to VOC system for preparation. Another gas nitrogen extrudes a methanol from metal formulation to the system.

\section{2) SENSOR: Semiconductor sensor Measured $\mathrm{CH}_{3} \mathrm{OH}$ (methanol)}

Semiconductor gas sensors utilize porous polycrystalline resistors made of semiconducting oxides. The working principle involves the receptor function played by the surface of each oxide grain and the transducer function played by each grain boundary. In addition, the utility factor of the sensing body also takes part in determining the gas response.

Therefore, the concepts of sensor design are determined by considering each of these three key factors. The requirements are selection of a base oxide with high mobility of conduction electrons and satisfactory stability (transducer function), selection of a foreign receptor which enhances surface reactions or adsorption of target gas (receptor function), and fabrication of a highly porous, thin sensing body (utility factor).

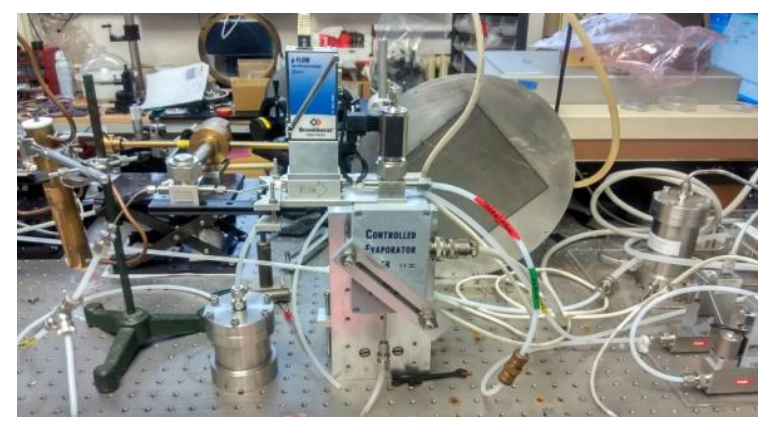

Fig. 2. Test set-up.

Thus, blended mixture then enters the pellistor. The output of the pellistor is connected to the pump that regulates the flow of the gas that passes through the pellistor. Pellistor is connected to the PC, which monitors \% LEL.

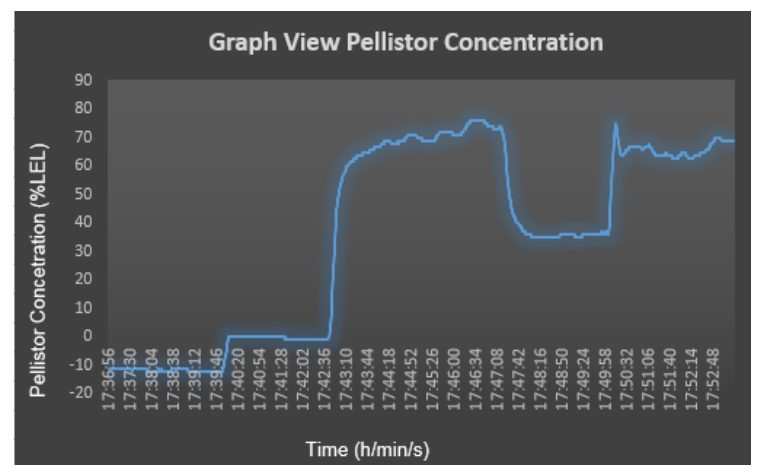

Fig. 3. Sensor response to different methanol concentration.

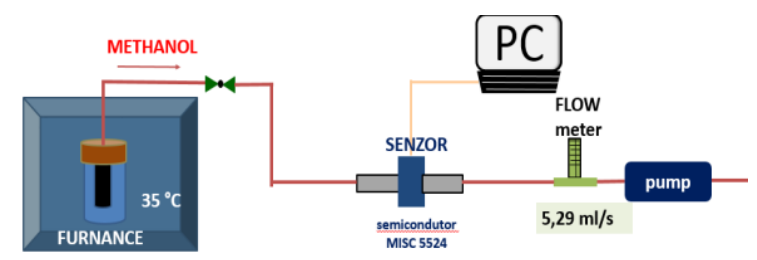

Fig. 4. Scheme of experimental arrangement.

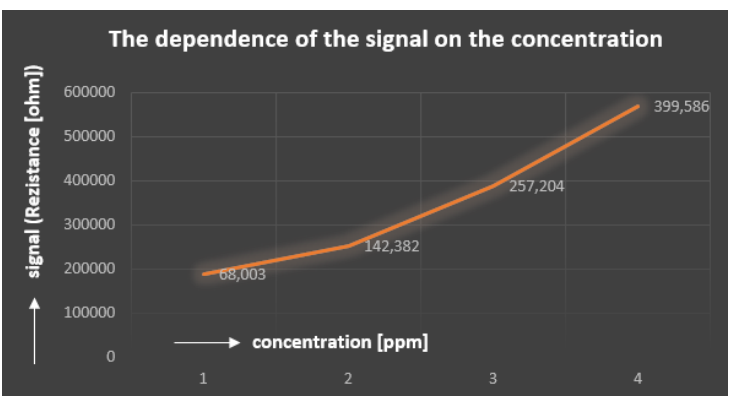

Fig. 5. The dependence of the signal on the concentration

The graph clearly shows that the higher concentration of the gas the stronger the signal.

3) SENSOR: Tunable diode laser - Measured $\mathrm{CH}_{4}$ absorption spectre

Tunable diode laser absorption spectroscopy (TDLAS) is a technique for measuring the concentration of certain species such as methane, water vapor and many more, in a gaseous mixture using tunable diode lasers and laser absorption spectrometry.

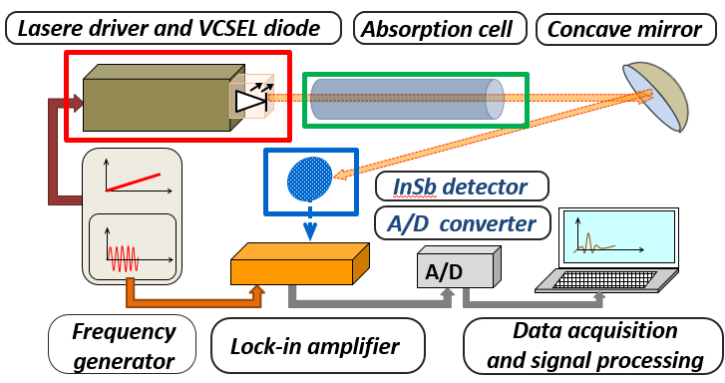

Fig. 6. Scheme of experimental arrangement. 
The basic principle behind the TDLAS technique is simple. The focus here is on a single absorption line in the absorption spectrum of a particular species of interest. To start with the wavelength of a diode laser is tuned over a particular absorption line of interest and the intensity of the transmitted radiation is measured.

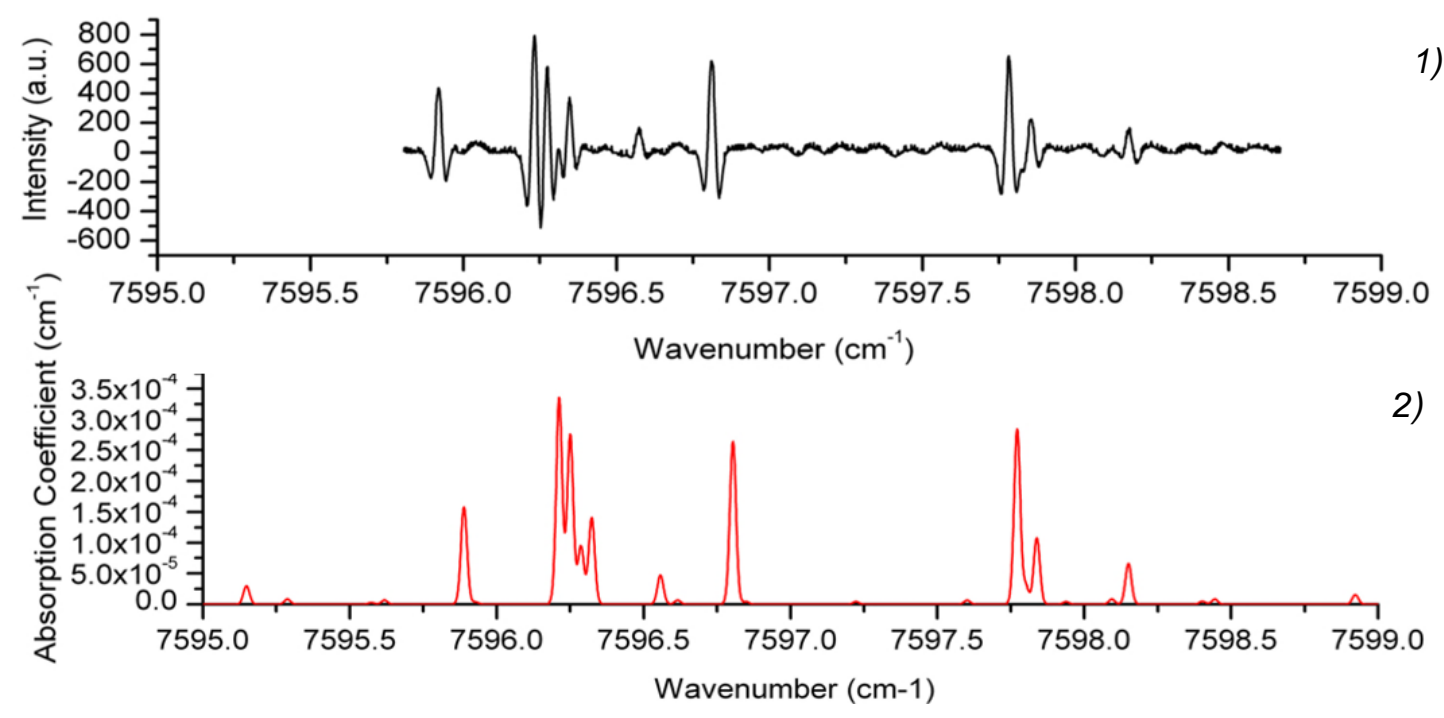

Fig. 7. Second-derivative (2f) methane absorption spectra 1) Measured at laboratory conditions. 2) Simulated based on HITRAN database (at $\mathrm{T}=300 \mathrm{~K}$ and $\mathrm{P}=0.01 \mathrm{~atm}$.

Tab. 1: A comparison of spectrometric methods and methods based on electrochemical principle.

\begin{tabular}{|c|c|c|c|}
\hline & Pellistor & Semiconductor sensor & $\begin{array}{c}\text { Tunable diode } \\
\text { sensor }\end{array}$ \\
\hline advantages: & $\begin{array}{l}\text { 1) The linear relationship } \\
\text { up to } 100 \% \text { LEL, } \\
\text { 2) Cheap and stable } \\
\text { sensor, } \\
\text { 3) High speed response } \\
\text { time }(<10 \mathrm{~s}) \\
\text { 4) Operating temperature } \\
\text { range }-40 \text { to }+60^{\circ} \mathrm{C}\end{array}$ & $\begin{array}{l}\text { 1) Durability and versatility, } \\
\text { 2) Suitable for binary } \\
\text { mixtures, } \\
\text { 3) High sensitivity for gases } \\
\text { with a higher thermal } \\
\text { conductivity ( } \mathrm{He}, \mathrm{H} 2, \mathrm{Ne} \text {, } \\
\mathrm{CH} 4 \text { ) } \\
\text { 4) Quick response }\end{array}$ & $\begin{array}{l}\text { 1) The detectors also } \\
\text { measured in an } \\
\text { atmosphere without } \\
\text { oxygen, } \\
\text { 2) They are not } \\
\text { harmed catalyst } \\
\text { poisons } \\
\text { 3) Warning of } \\
\text { contamination of the } \\
\text { optics, } \\
\text { 4) Quality detectors } \\
\text { operate up to } 80 \% \\
\text { contamination of the } \\
\text { optics, } \\
\text { 5) Good selectivity }\end{array}$ \\
\hline disadvantages: & $\begin{array}{l}\text { 1) Susceptibility to poison } \\
\text { the catalyst thereby } \\
\text { reducing sensitivity } \\
\text { 2) For its operation } \\
\text { requires an atmosphere } \\
\text { containing min. } 10 \% \\
\text { oxygen, "poison" pellistor } \\
\text { gives a signal at zero } \\
\text { concentration, therefore it } \\
\text { is necessary to verify the } \\
\text { calibration gas, } \\
\text { 3) Increased energy } \\
\text { demands. }\end{array}$ & $\begin{array}{l}\text { 1) The output signal is } \\
\text { greatly influenced by a } \\
\text { change in ambient } \\
\text { temperature } \\
\text { 2) On the other hand, they } \\
\text { are more susceptible to } \\
\text { interference by other gases } \\
\text { than other types of sensors } \\
\text { 3) Not for multi- } \\
\text { component gas mixtures } \\
\text { 4) Present gases with lower } \\
\text { thermal conductivity than } \\
\text { air cause interference } \\
\text { 5) Gases with relative } \\
\text { thermal conductivity close } \\
\text { to } 1 \text { are not measurable } \\
\text { (CO, O2, N2, NH3) }\end{array}$ & 1) High price \\
\hline
\end{tabular}




\section{Conclusion \& Outlook}

The progress in Tunable Diode Laser Absorption Spectroscopy (TDLAS) leads to the development of detection system with good reliability, superior response time, high accuracy even at very low concentrations of gases (ppb) and reasonable price.

Spectrometry based detection techniques are rapidly expanding along with the emerging technical capabilities. The progress in Tunable Diode Laser Absorption Spectroscopy (TDLAS) leads to the development of detection system with good reliability, superior response time, high accuracy even at very low concentrations of gases (ppb) and reasonable price [1].

Electrochemical sensors are used primarily in the measurement of oxygen and low concentrations of toxic gases. They are characterized by very good selectivity relatively to semiconductor sensors. The disadvantage is limited lifetime, cross-interference and the possibility of damage due to the high concentration of gas. Semiconductor sensors detect a broad spectrum of gases. They have very long lifetime, they can detect both low and high concentrations of gases, the key advantage is its very low price. Their disadvantage is particularly strong dependence on humidity, temperature and flow, as well as poor selectivity. However with proper mathematical analysis of required signals, the selectivity can be significantly enhanced. These mathematical methods use all possible information from the signal, including its time profile [2]. A comparison of the performance is reported in table 1.

\section{Acknowledgements}

The authors are grateful to the financial support from Project No. 14-14696S funded by the Czech Science Foundation and Project No. LD14022 within COST Action TD1105 funded by the Ministry of Education, Youth and Sports of the Czech Republic.

\section{References}

[1] Hodgkinson, R. P. Tatam, "Optical gas sensing: a review", Measurement science and technology, 24 (2013) 012004.

[2] H. Nasim, Y. Jamil, "Recent advancements in spectroscopy using tunable diode lasers", Laser physics letters, 10 (2013) 043001.

[3] H. Nasim, Y. Jamil, "Recent advancements in spectroscopy using tunable diode lasers", Laser physics letters, 10 (2013) 043001. 